\title{
Application of Simulation Methods for Evaluating the Sea Waterways Traffic Organisation
}

\author{
Agnieszka Blokus-Roszkowska and Leszek Smolarek \\ Mathematics Department, Gdynia Maritime University, Morska 81-87, 81-225 Gdynia, Poland \\ Correspondence should be addressed to Agnieszka Blokus-Roszkowska; ablokus@am.gdynia.pl
}

Received 3 June 2013; Accepted 2 July 2013

Academic Editors: H. Homeier, M.-H. Hsu, Z. Huang, and M. Qatu

Copyright (c) 2013 A. Blokus-Roszkowska and L. Smolarek. This is an open access article distributed under the Creative Commons Attribution License, which permits unrestricted use, distribution, and reproduction in any medium, provided the original work is properly cited.

\begin{abstract}
Maritime transport is of great importance as it is the basis of international trade. Shipping is a global industry and highly complex business. Further safety development at sea is determined by the growth of maritime traffic intensity. Therefore, new ideas and technologies are needed to optimize the sea transport system. In the paper, the cellular automaton model is suggested to describe traffic flow at grade roundabout and simple crossing. Not only the cell state but also neighborhood as well is defined for presented cellular automaton. The model, describing vessels motion, takes into account vessel's type, speed and length, vessel's behavior and maneuverability, lane status, and flow density. It provides the basis for simulation. Two types of traffic schemes, namely, roundabout and simple routes crossing, are considered. Some results of simulation, including ships safety prediction, illustrate possible applications for evaluation of maritime traffic organization. Final conclusion and remarks outline further work development.
\end{abstract}

\section{Introduction}

Every human activity is associated with the risk of leading to the possibility of a loss. Therefore, due to the phenomenon of risk aversion, we try to optimize risk. This requires the measurement of risk, that is, used risk measure. Rational decisionmaking is based on risk management [1]. Selection of risk measures is an important issue because the wrong measure or model can lead to overestimation or underestimation of the actual risk.

Using a mathematical model of a real object is one of the features of scientific research. The model enables the universalization of the different processes and examining any large set of objects. In some cases, the use of models is necessary due to the inability to carry out any form of experiment. Formal recognition of reality also creates the conditions to conduct extensive research on the problem of interest to us and greatly reduces the cost of the research process. Decision making is the process of recognizing a problem and finding a solution to it. Many of these decisions are relatively simple, but there are some decisions where neither the appropriate solution nor the potential outcome is known $[1,2]$.

In maritime transport, we can distinguish five basic steps: leaving the port, opening water, limiting water bodies to the port of entry (transition fairway, turntable, head, and mooring), loading, and unloading operations. These steps occur sequentially, so we can make the decomposition of risk listed five steps to facilitate analysis and to determine the sources and hierarchy of threats. One of the elements in the stage of open water is the crossing of sea waterways.

Sea transport safety improvement and ship collision avoidance are an important research domain in maritime science. In this topic, many papers are focused on trajectory planning and collision avoidance systems with support of simulation methods [3-5]. Other papers present new ideas and results of ship collision probability modeling that can predict the accidence occurrence and provide detailed information about vessels colliding with each other [6-9]. The analysis presented in this paper focuses on estimating the probability of potential collision and potentially dangerous situation occurrence on the level of traffic organization. 
In the presented model, there are considered different traffic cases with changing crossing's geometry, traffic flow structure, and parameters.

Navigation is becoming more and more complicated task demanding a balance point between navigation safety and economics. Cargo transport is increasing rapidly, and the waterways are more congested. This might cause reduction of maneuvering options. A wide-ranging variety of operational data and information must be correlated and mentally assessed by ship operators. To face the logistical organization, it is necessary to apply new alternative solutions for operational optimization $[10,11]$.

\section{Cellular Automaton Model}

Cellular automata (CA) are very efficient way to implement not only vehicles or vessels motion but also other fields such as pedestrian behavior, escape and panic dynamics, the spreading of forest fires, and material properties $[12,13]$. The cellular automata approach is also useful in emulating the way the laws of priority are supposed to work in roundabout [14]. In this paper, the CA are applied to vessels flow modeling in the area of open sea waterways' crossing. Cellular automata models could give us an idea of how hazard of collision influences the shipping safety even if they emulate nature in more than a rough way.

2.1. Crossing's Geometry. This paper describes simple crossing with distinguished main flow having priority [15] and roundabout with three different scenarios of vessels' priority. First case, when the vessel having the other vessel on its own starboard side will keep out of the way. In the second scenario, we assume that traffic lanes 1 and 3 are main routs with standon vessels, and on routs 2 and 4 there are give-way vessels that should keep out of the way of vessels being on routs 1 and 3. The last considered situation is when vessel being on roundabout-lane has priority and vessel entering roundabout crossing is directed to keep out of the way.

In a maritime traffic scenario with a roundabout, we consider a junction of four routes numbered 1,2,3, and 4 and four points of potential collision (Figure 1). We assume that traffic lanes 1 and 3 are main routes on that there are usually large vessels with less maneuverability. In the simulation model, we assume that distances between collision points are equal to 1 nautical mile $(\mathrm{nm})$. Vessels are observed in lanes entering roundabout-lane with a distance to $6 \mathrm{~nm}$. The traffic lanes are divided into cells. The spatial discretization corresponds to vessels' lengths, whereas the temporal discretization is based on vessels' velocities and a cell size.

2.2. Definition of the Cellular Automaton. In our model, the cellular automaton (CA) is a $2 \mathrm{D}$ grid of identically programmed cells, which interact with one another. The cells are arranged according to shape of roundabout crossing or simple crossing.

The cell is the basic element of a CA. It is a kind of a memory element. In the simplest case, each cell can have the

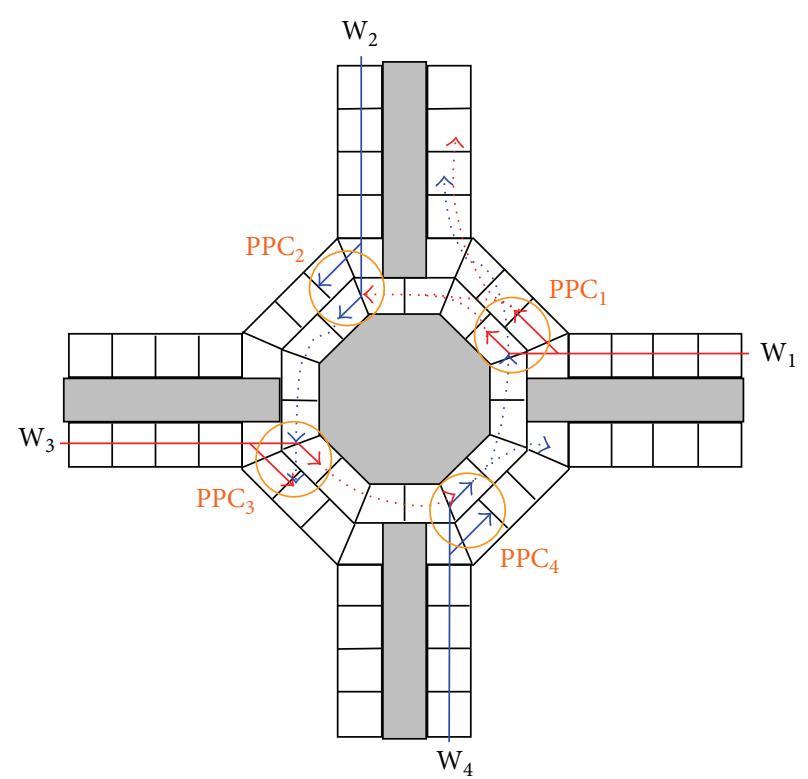

$\mathrm{W}_{1}, \mathrm{~W}_{2}, \mathrm{~W}_{3}, \mathrm{~W}_{4}$-enter lines for roundabout

$\mathrm{PPC}_{1}, \mathrm{PPC}_{2}, \mathrm{PPC}_{3}, \mathrm{PPC}_{4}$ - potential points of collision

FIGURE 1: The scheme of grade roundabout crossing.

binary states 1 or 0 . In more complex simulation, the cells can have more different states.

The basic features of a cellular automaton are

(i) State-the variable that takes a different separate value for each cell. The state can be either a number or a property. Each cell represents part of a roundabout or simply crossing, and the state represents the "number" of ships at each location.

(ii) Neighbourhood-the set of cells that it interacts with. In a grid, these are the cells physically imported at collision hazard to the cell in question (Figure 2).

Rules. The state of the next state core cell is only dependent upon the states of the neighbourhood cells. An example of state changes is given in Figure 3.

2.2.1. Neighbourhood for the Roundabout. Different definition of neighborhoods are possible. Considering a twodimensionals grid of the roundabout, the following definitions are used.

(I) Neighbourhood-four cells, the cell below, two right, and one left, from the cell $\mathrm{C}$ are called the type I neighbourhood of this cell. The ship at this definition is going around (Figure 4). Rules: to make the move, the cells on right and left should be empty.

(II) Neighbourhood-three cells, two cells above, and one cell below, from the cell $\mathrm{C}$ are called the type II neighbourhood of this cell. The ship at this definition is going to roundabout (Figure 5). Rules: to make the move, the cells above should be empty. 


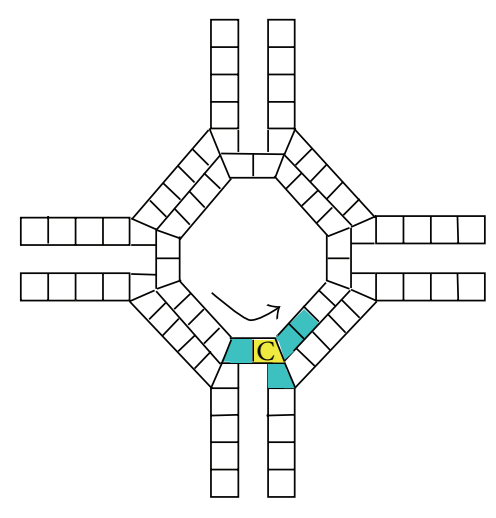

I

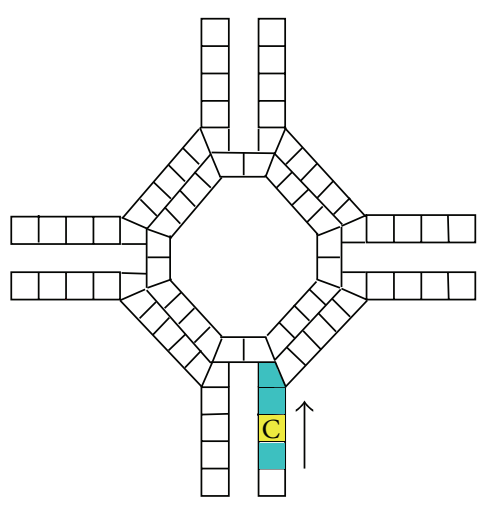

II

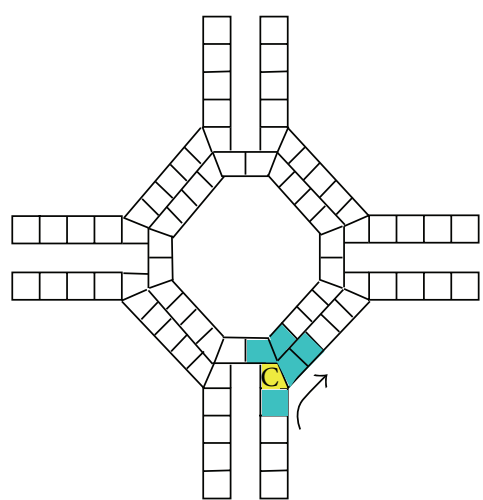

III

FIGURE 2: Some neighbourhoods (cells marked blue) of a cell marked yellow (C) in the 2D grid of roundabout.
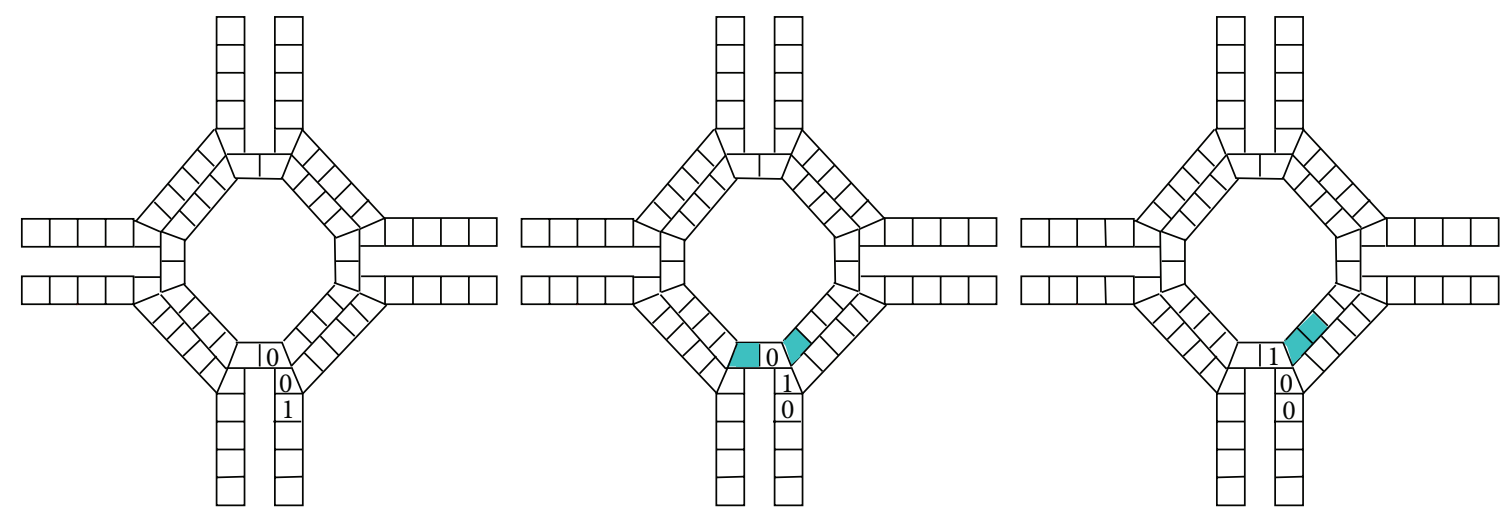

Figure 3: An example of state changes (cells marked blue are important at non binary cells case) in the 2D grid of roundabout.

(III) Neighbourhood-five cells, two cells above, one cell below, and two cells right, from the cell $\mathrm{C}$ are called the type III neighbourhood of this cell. The ship at this definition is going right at roundabout (Figure 6). Rules: to make the move, the cells on right and left above should be empty.

2.2.2. Neighbourhood for the Simple Crossing. For a two dimensional grid of the simple crossing we distinguish the following types of neighbourhood.

(I) Neighbourhood-three cells, two cells above and one cell below, are called the type I neighbourhood of this cell (Figure 7). Rules: to make the move, the cells above should be empty.

(II) Neighbourhood-four cells, two cells above, a cell below, and one cell left above, from the cell C are called the type II neighbourhood of this cell (Figure 8). Rules: to make the move, the cells on above and left above should be empty;

(III) Neighbourhood-four cells, two cells above, one cell below, and one cell right above from the cell $\mathrm{C}$ are called the type III neighbourhood of this cell (Figure 9). Rules: to make the move, the cells on right above and above should be empty.

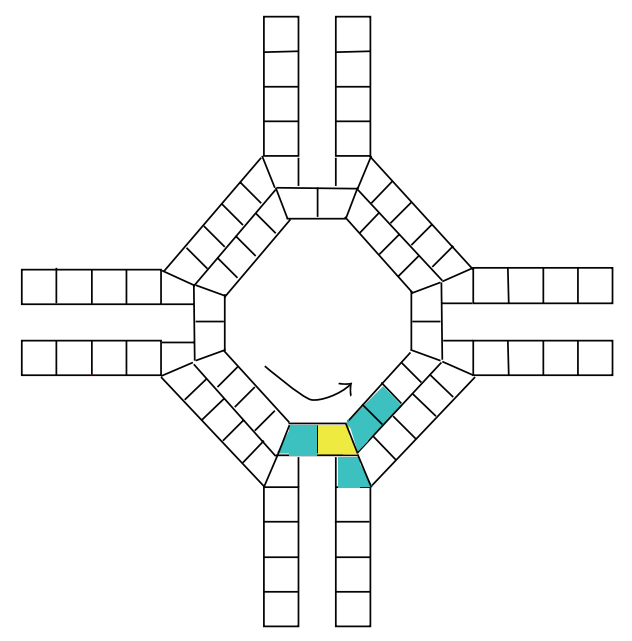

FIgURE 4: The neighbourhood type I (cells marked blue) of a cell with a ship (marked yellow) in the $2 \mathrm{D}$ grid of roundabout.

The set of rules defines how the cell $\mathrm{C}$ state changes in response to its current state and that of its neighbours. According to the previous definition of the state in the presented cellular automaton model, we assume the cell's state can be equal to 0 or 1 . 


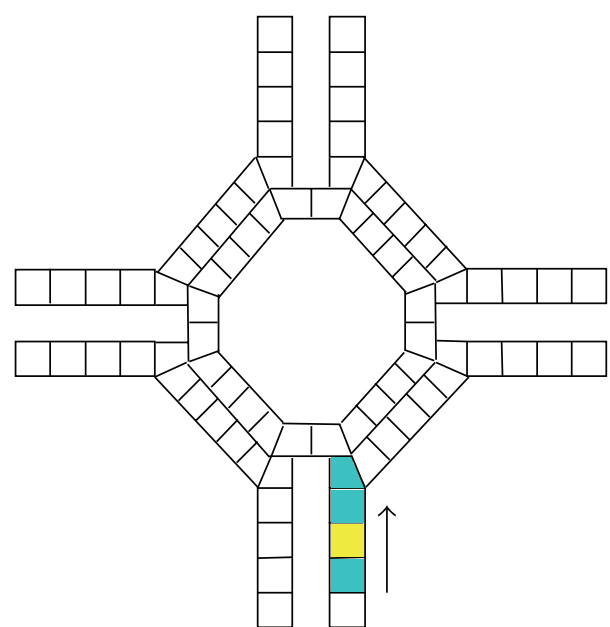

FIGURE 5: The neighbourhood type II (cells marked blue) of a cell with a ship (marked yellow) in the $2 \mathrm{D}$ grid of roundabout.

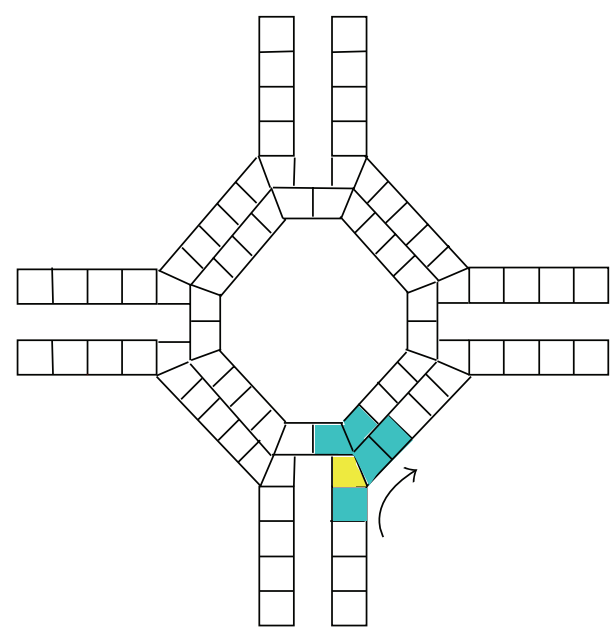

Figure 6: The neighbourhood type III (cells marked blue) of a cell with a ship (marked yellow) in the $2 \mathrm{D}$ grid of roundabout.

2.3. Risk Levels. The length of cell is determined similarly as in the Nagel-Schreckenberg model $[16,17]$; however, we assume that it is not constant for each performed simulation. In our model, the length of cell depends on flows' intensities, vessels' velocities, and lengths and can be determined according to the following formula:

$$
\mathrm{CS}=\rho_{\text {cross }}^{-1}, \quad \rho_{\text {cross }}=\max \left\{\rho_{12}, \rho_{14}, \rho_{32}, \rho_{34}\right\}
$$

where $\rho_{12}=\sqrt{\rho_{1}^{2}+\rho_{2}^{2}}, \rho_{14}=\sqrt{\rho_{1}^{2}+\rho_{4}^{2}}, \rho_{32}=\sqrt{\rho_{3}^{2}+\rho_{2}^{2}}$, $\rho_{34}=\sqrt{\rho_{3}^{2}+\rho_{4}^{2}}$, and $\rho_{1}=\mathrm{LOA}_{1} /\left(T_{1} \cdot V_{1}+\mathrm{LOA}_{1}\right), \rho_{2}=$ $\mathrm{LOA}_{2} /\left(T_{2} \cdot V_{2}+\mathrm{LOA}_{2}\right), \rho_{3}=\mathrm{LOA}_{3} /\left(T_{3} \cdot V_{3}+\mathrm{LOA}_{3}\right)$, $\rho_{4}=\mathrm{LOA}_{4} /\left(T_{4} \cdot V_{4}+\mathrm{LOA}_{4}\right), \mathrm{LOA}_{i}$ - a length of vessels moving on $i$-the waterway, $V_{i}$-a velocity of vessels moving on $i$-the waterway, and $T_{i}$-mean time between consecutive ships' starting on $i$-the waterway.
Next we define the following ships' safety states corresponding to risk levels depending on mutual distance of vessels that are on collision courses:

(i) state 3 (negligible risk of collision) - both ships being in cells are in a safety distance defined as $2 \mathrm{~nm}$; that is, the number of cells being in state 0 between two ships is equal at least to $d_{3}$, determined from the formula

$$
d_{3}=\left\lceil\frac{2 \cdot 1852}{\mathrm{CS}}\right\rceil \text {, }
$$

where $\lceil d\rceil$ denotes the integer part of number $d$ plus 1 and CS is a cell size;

(ii) State 2 (low risk of collision) - both ships being in cells are in a distance of passing clear Closest Point of Approach (CPA), assumed to be equal to $1 \mathrm{~nm}$ $(1852 \mathrm{~m})$; it means that the number of cells being in state 0 between two ships is equal at least to $d_{2}$, where $d_{2}$ is given by the formula

$$
d_{2}=\left\lceil\frac{1852}{\mathrm{CS}}\right\rceil
$$

(iii) state 1 (high risk of collision) - both ships being on collision courses are in cells in a distance concerned with their domains [18], and the number of cells being in state 0 between two ships is equal at least to $d_{1}$, where $d_{1}$ is defined by the formula

$$
d_{1}=\left\lceil\frac{4 \mathrm{LOA}_{M_{-} \max }+4 \mathrm{LOA}_{L_{-} \max }}{\mathrm{CS}}\right\rceil \text {, }
$$

where $\mathrm{LOA}_{M_{-} \max }=\max \left\{\mathrm{LOA}_{1}, \mathrm{LOA}_{3}\right\}, \mathrm{LOA}_{L_{-} \max }=$ $\max \left\{\mathrm{LOA}_{2}, \mathrm{LOA}_{4}\right\}$;

(iv) state 0 (collision alert) - defined as a situation of two vessels domains' overlapping; that is, the number of cells being in state 0 between two ships is lower than $d_{1}$ defined by (4).

\section{Simulation Data and Assumptions}

3.1. Vessels' Parameters and Behavior. We consider the following major ship types: a tanker, a container carrier, a passenger ship, a RoPax, a general cargo ship, and fast ferry. For each class of vessel on main and lateral routes, vessel velocity is taken into the model by random sampling according to fitted, on the basis of data recorded in Gulf of Finland, distribution [19]. In the simulation as input length of ship, we assumed the mode for considered types of vessel using collected data.

Different types of ships do not act in the same way; the slowest vessels tend to keep their course and speed, even if they have to move. The faster cargo ships such as ferries alter their course in compliance with the regulations. Nevertheless, a ferry may follow informal rules, for example, in case it is stand-on vessel. Then he/she may perform an action, even if the rule requires him/her to keep his/her course and speed, that can cause another collision situation.

In the simulation, we assume a priori probability of taking evasive action by give-way and stand-on vessels according 

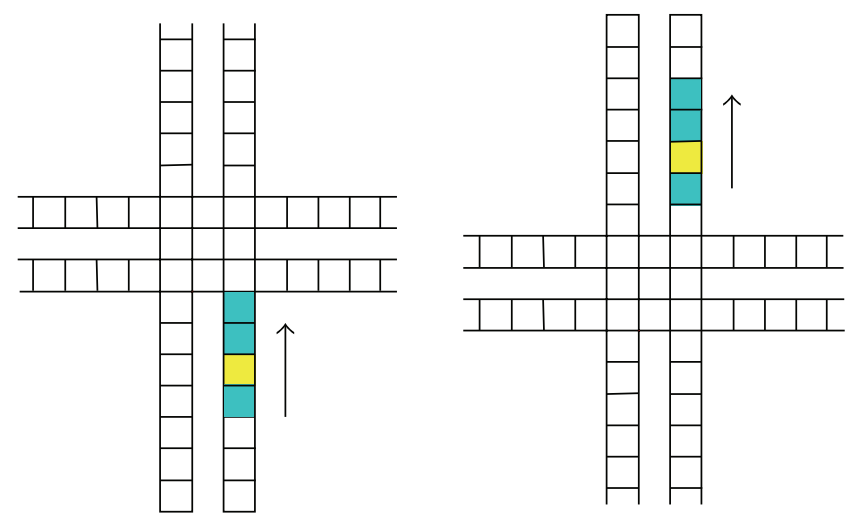

FIGURE 7: The neighbourhood type I (cells marked blue) of a cell with a ship (marked yellow) in the 2-D grid of simple crossing.

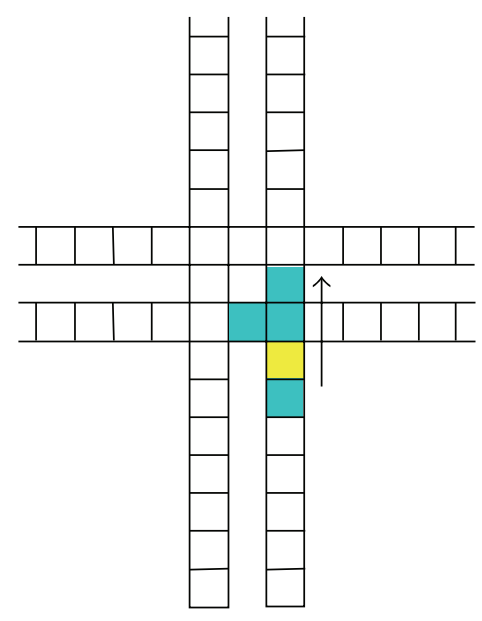

FIgURE 8: The neighbourhood type II (cells marked blue) of a cell with a ship (marked yellow) in the 2-D grid of simple crossing.

to vessels' behavior modeling conducted in [20]. This probability is randomly chosen from fixed interval depending on vessel's type and velocity in case it is a stand-on and give-way vessel.

We denote the probability of taking evasive action by give-way vessel by $p_{E A \_G W}$ and for stand-on vessel by $p_{E A \_S O}$, equivalently. We use the notation $d$ for distance of vessels being on collision courses. Further, we assume that in case the risk of collision is negligible $\left(d \geq d_{3}\right)$, give-way vessel will take evasive action with probability $0.5 p_{E A-G W}$, otherwise $\left(d<d_{3}\right)$ with probability $p_{E A_{-} G W}$. In case the risk of collision is high $\left(d<d_{2}\right)$, we assume stand-on vessel will start evasive action with higher probability than mentioned before; that is, $2 p_{E A S O}$ if $p_{E A S O}<0.5$ and 1 if $p_{E A S S O} \geq 0.5$, otherwise $\left(d_{2} \leq d<d_{3}\right)$ with probability $p_{E A S S O}$. Figure 10 illustrates the behavior of stand-on and give-way vessels in terms of maneuvering.

In simulation, we assume that ship performs a collision avoidance maneuver in time not shorter than passing distance of three ships' lengths. Total time of taking evasive action and time to reach collision point cannot be shorter

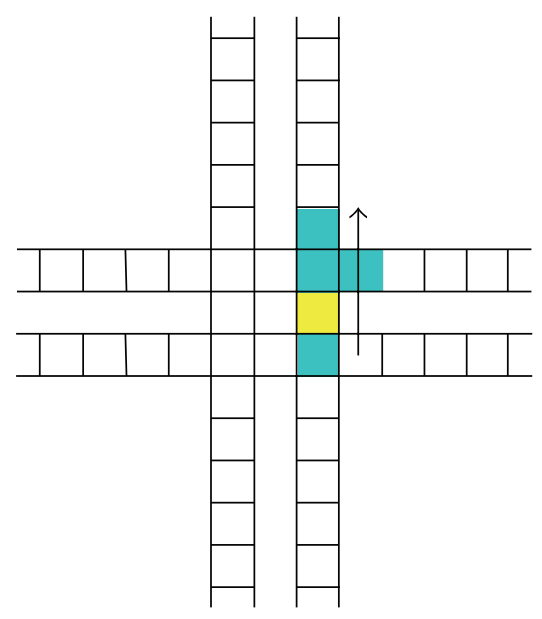

FIGURE 9: The neighbourhood type III (cells marked blue) of a cell with a ship (marked yellow) in the 2-D grid of simple crossing.

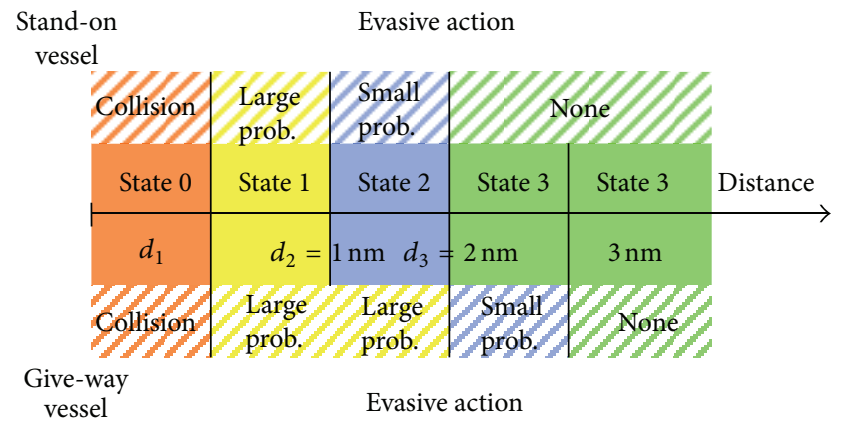

FIGURE 10: The probability of taking evasive action by give-way and stand-on vessels.

than time of passing collision point by the second ship with a safe distance of ship domain that is distance $d_{1}$.

3.2. Traffic Flows' Parameters. On the basis of system flows analysis, presented in [21], the input data for simulation program are randomly chosen with assumed mean value and standard deviation for each flow. In simulation, the 
ships' starting times can follow different distribution. We can choose these distributions on main and lateral waterways from the following list: deterministic, uniform, exponential, Erlang, normal, log-normal, Beta, gamma, and triangular.

\section{Simulation Program}

4.1. Simulation Procedure. In simulation, we compare time to point of collision expressed in time steps. If time of vessels being on collision courses is shorter than time of vessels reaching collision point and none of vessels take evasive action at this moment, we check the distance between vessels. Then we compare obtained distance with the threshold values of safety states defined before, and according to this definition, we give vessels' status states. If the vessel's status state has changed, this information is saved along with time after that transition has occurred, that is, time during which ship was in the previous safety state. If the ship on main waterway is not fully safe, the system also examines next ships on this waterway.

The procedure of checking collision point in details is as follows [22]:

(I) if there are vessels on collision courses, then take the first ship from both waterways, that is, ship being on roundabout-lane and ship on collision route entering roundabout;

(II) check if any of these ships perform collision avoidance maneuver;

(a) if yes

do \{

check whether evasive action is finished

(1) if yes change status of the ship evasive action to false;

(2) else take the next ship from the list of ships on waterway

\} while ( ship evasive action $=$ true)

repeat the above procedure for give-way and stand-on vessels;

(b) else//no ship performs collision avoidance maneuver;

check if any of ships crossed collision point;

(c) if not determine the distance between ships $d$

(1) if $d<d_{1}$, change the ship's state to state 0 (collision alert) and save time of ships being in the previous state in case ship was in state better than 0 ;

(2) else if $d<d_{2}$, change the ship's state to state 1 and save time of this change similarly as in case $d<d_{1}$.

Check if the distance between ships, when they will be crossing collision point, is larger than collision alert distance;

(i) if not, then with assumed a priori probability give-way and stand-on vessels can take evasive action;
(3) else if $d<d_{3}$, change the ship's state to state 2 if it differs and save time of this change as before;

check if the distance between ships, when they will be crossing collision point, is larger than collision alert distance;

(i) if not, then with assumed a priori probability give-way, and stand-on vessels can take evasive action;

(4) else $\left(d \geq d_{3}\right)$ change the ship's state to state 3 if it differs and save time of this change as before,

(i) if $d<3 \mathrm{~nm}$, determine the distance between ships, when they will be crossing collision point;

(ii) check if this distance is larger than collision alert distance (corresponding to ship's domain) and in case it is not, then give-way vessel with assumed a priori probability will take evasive action;

if the ship's state is worse than 3, check the risk of potential collision at considered collision point for the next ship;

check the situation at considered collision point after time step;

(d) else//ship on waterway has just crossed collision point;

note that the other ship is safe; if the ship's state is worse than 3 change it to state 3 , and save time of ships being in the previous state;

check considered collision point for the next ship, and in case the ship that has just crossed the collision point is still on roundabout, $t$ check simultaneously situation to the next collision point for this ship;

(III) else//there is no ship on one of the collision routes; note that the ship on the other route is safe; if the ship's state is worse than 3 change it to state 3 , and save time of ships being in the previous state;

(a) check if the ship has crossed collision point;

(1) if yes, in case the ship is still on roundabout, check situation to the next collision point;

(2) else

check the situation at considered collision point after time step.

4.2. Simulation Results. Presented program is not devoted to ship collision avoidance route planning, but it focuses on counting probability of ships collision in given situation. Namely, from simulation, both probabilities of ship collision and probabilities of occurrence of high, low, or negligible risk of collision are given. The simulation program is capable of 


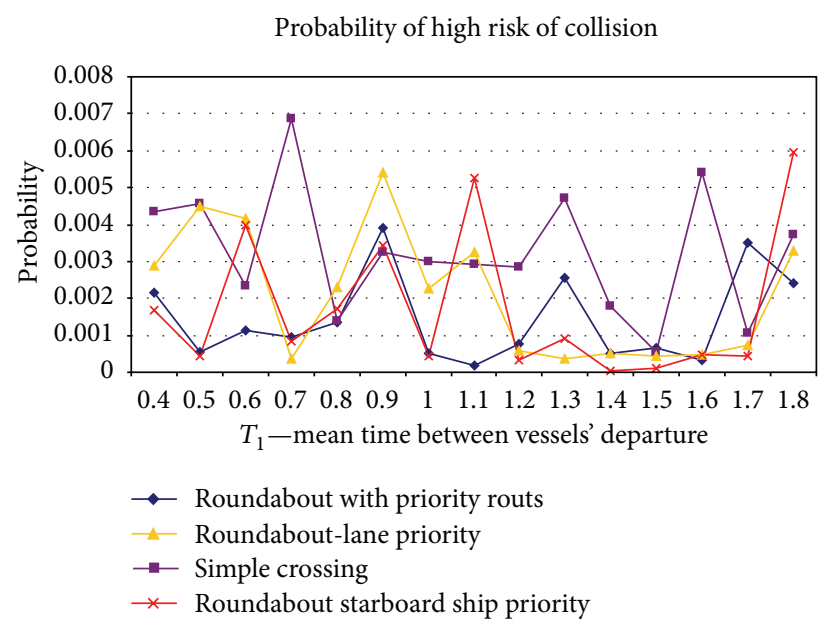

FIGURE 11: The probability of high risk of collision depending on mean time between vessels' departure at waterway 1 for different traffic schemes.

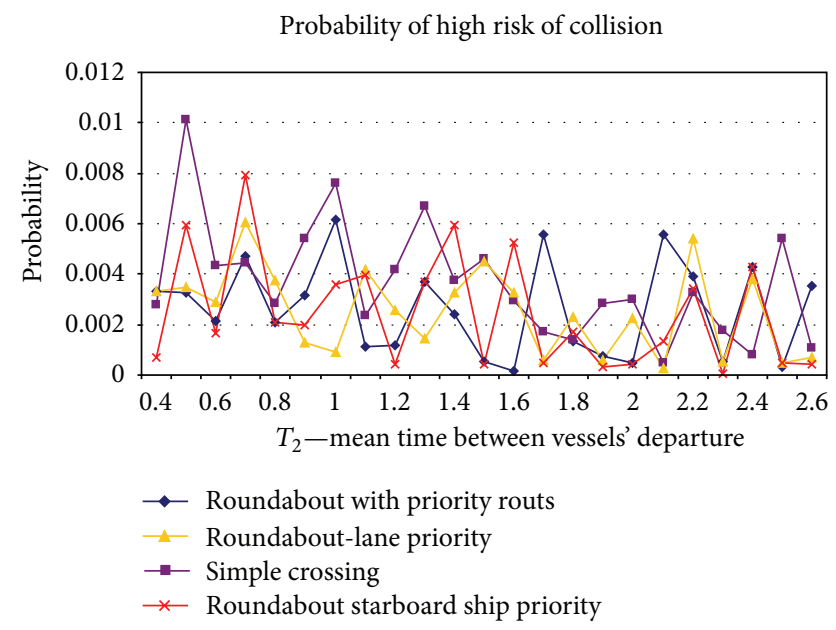

FIGURE 12: The probability of high risk of collision depending on mean time between vessels' departure at waterway 2 for different traffic schemes.

determining matrix of system transitions' number between states and realizations of conditional sojourn times at the state until transition to the other state. From these results, there are also determined matrices of probabilities of system's transitions between the states and vector of probabilities of system's being in the particular states during simulation time.

The proposed simulation model are sensitive to its changing parameters, that is depicted at graphs (Figures 11 and 12). Thus, the distribution of input data must be properly defined and analyzed.

The simulation results are describing how ships' safety is depending on traffic flows structure and parameters. The simulation was performed for different traffic schemes and priority scenarios, defined before. The results clearly show the influence of traffic organization on probability of collision risk (Table 1).
TABLE 1: Results of a case study and effect of different traffic schemes organization.

\begin{tabular}{lcccc}
\hline Traffic scenario* & I & II & III & IV \\
\hline \multicolumn{5}{c}{ Probability of negligible risk of collision } \\
Mean value & 0.7937 & 0.9411 & 0.9410 & 0.9372 \\
Standard deviation & 0.0021 & 0.0203 & 0.0210 & 0.0200 \\
\hline \multicolumn{5}{c}{ Probability of low risk of collision } \\
Mean value & 0.2001 & 0.0513 & 0.0514 & 0.0572 \\
Standard deviation & 0.0466 & 0.0190 & 0.0196 & 0.0171 \\
\hline \multicolumn{5}{c}{ Probability of high risk of collision } \\
Mean value & 0.0035 & 0.0031 & 0.0030 & 0.0029 \\
Standard deviation & 0.0057 & 0.0036 & 0.0044 & 0.0038 \\
\hline \multicolumn{5}{c}{ Probability of collision alert } \\
Mean value & 0.0027 & 0.0031 & 0.0033 & 0.0014 \\
Standard deviation & 0.0021 & 0.0037 & 0.0044 & 0.0025 \\
\hline
\end{tabular}

${ }^{*}$ I: simple crossing, II: roundabout with priority routs, III: roundabout-lane priority, and IV: roundabout starboard ship priority.

In the future research, that will be based on real data, this model will be expanded and the detailed comparison of maritime traffic flows for different crossing geometry and structure will be performed.

At the next step, the regression model could be built on the statistical analysis with regard to type distribution's identification. The simulation results can also illustrate that particular variables have significant influence on the probability of collision risk. Future investigation could consider traffic organization as well as the distance between collision point. This could be crucial from safety management's point of view.

\section{Conclusions}

Using simulation methods makes assessing the risk of conflict in a given situation by an external observer possible. It can determine which ships can cause collision's risk. Depending 
on the traffic flow parameters, simulation approach also allows analyzing how the traffic organization affects safety. As a beginning of this work, the paper introduces the model of basic cellular automaton for the description of maritime traffic flow and brief view of how it can be useful in the maritime transport safety analysis. Cellular automaton, presented in this paper, focuses on system dynamics modeling and examination of ships' routes crossing. Detailed analysis of the simulation results for different traffic schemes can be effectively used in evaluating the sea waterways traffic organization and optimization. Thereby, the simulation model with some further development can be helpful as a tool on the level of safety management or safety-based spatial planning of sea areas.

\section{References}

[1] A. Oltedal Helle, Safety culture and safety management within the Norwegian-controlled shipping industry [Ph.D. thesis], University of Stavanger, N-4036 Stavanger, Stavanger, Norway, 2011.

[2] C. Hetherington, R. Flin, and K. Mearns, "Safety in shipping: the human element," Journal of Safety Research, vol. 37, no. 4, pp. 401-411, 2006.

[3] B. A. Colley, "A marine traffic flow and collision avoidance computer simulation," The Journal of Navigation, vol. 37, no. 2, pp. 232-250, 1984.

[4] T. Statheros, G. Howells, and K. McDonald-Maier, "Autonomous ship collision avoidance navigation concepts, technologies and techniques," Journal of Navigation, vol. 61, no. 1, pp. 129-142, 2008.

[5] M.-C. Tsou and C.-K. Hsueh, "The study of ship collision avoidance route planning by ant colony algorithm," Journal of Marine Science and Technology, vol. 18, no. 5, pp. 746-756, 2010.

[6] T. Macduff, "The probability of vessel collisions," Ocean Industry, vol. 9, no. 9, pp. 144-148, 1974.

[7] F. Goerlandt and P. Kujala, "Traffic simulation based ship collision probability modeling," Reliability Engineering and System Safety, vol. 96, no. 1, pp. 91-107, 2011.

[8] K. Inoue and M. Kawase, "Innovative Probabilistic prediction of accident occurrence," in Editor, Marine Navigation and Safety of Sea Transportation, A. Weintrit, Ed., Taylor and Francis, London, UK, 2007.

[9] T. G. Fowler and E. Sørgård, "Modeling ship transportation risk," Risk Analysis, vol. 20, no. 2, pp. 225-244, 2000.

[10] Y. Xue, B. S. Lee, and D. Han, "Automatic collision avoidance of ships," Proceedings of the Institution of Mechanical Engineers Part M, vol. 223, no. 1, pp. 33-46, 2009.

[11] C.-M. Su, K.-Y. Chang, and C.-Y. Cheng, "Fuzzy decision on optimal collision avoidance measures for ships in vessel traffic service," Journal of Marine Science and Technology, vol. 20, no. 1, pp. 38-48, 2012.

[12] S. Wolfram, Theory and Application of Cellular Automata, World Scientific, Singapore, 1986.

[13] S. Maerivoet and B. De Moor, "Cellular automata models of road traffic," Physics Reports A, vol. 419, no. 1, pp. 1-64, 2005.

[14] R.-X. Chen, K.-Z. Bai, and M.-R. Liu, "The CA model for trafficflow at the grade roundabout crossing," Chinese Physics, vol. 15, no. 7, pp. 1471-1476, 2006.

[15] A. Blokus-Roszkowska and L. Smolarek, "Collision risk estimation for motorways of the sea, Reliability," Theory \& Applications, vol. 1, no. 2, supplement 25, pp. 58-68, 2012.
[16] K. Nagel and M. Schreckenberg, "A cellular automaton model for freeway traffic," Journal de Physique I France, vol. 2, no. 12, pp. 2221-2229, 1992.

[17] J. Wahle, L. Neubert, J. Esser, and M. Schreckenberg, "A cellular automaton traffic flow model for online simulation of traffic," Parallel Computing, vol. 27, no. 5, pp. 719-735, 2001.

[18] Y. Fujii and K. Tanaka, “Traffic capacity," Journal of Navigation, vol. 24, pp. 543-552, 1971.

[19] J. Montewka, T. Hinz, P. Kujala, and J. Matusiak, "Probability modelling of vessel collisions," Reliability Engineering and System Safety, vol. 95, no. 5, pp. 573-589, 2010.

[20] C. Chauvin and S. Lardjane, "Decision making and strategies in an interaction situation: collision avoidance at sea," Transportation Research F, vol. 11, no. 4, pp. 259-269, 2008.

[21] A. Blokus-Roszkowska, J. Montewka, and L. Smolarek, "Modelling the accident probability in large-scale, maritime transportation system," Journal of Polish Safety and Reliability Association, Summer Safety and Reliability Seminars, vol. 3, no. 2, pp. 237-244, 2012.

[22] F. Howell and R. McNab, "SimJava: a discrete event simulation library for Java," in Proceeding of the first International Conference on Web-Based Modelling and Simulation, pp. 51-56, 1998. 


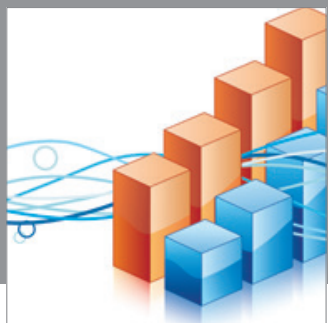

Advances in

Operations Research

mansans

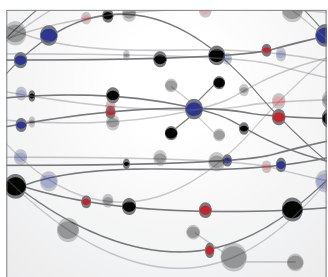

The Scientific World Journal
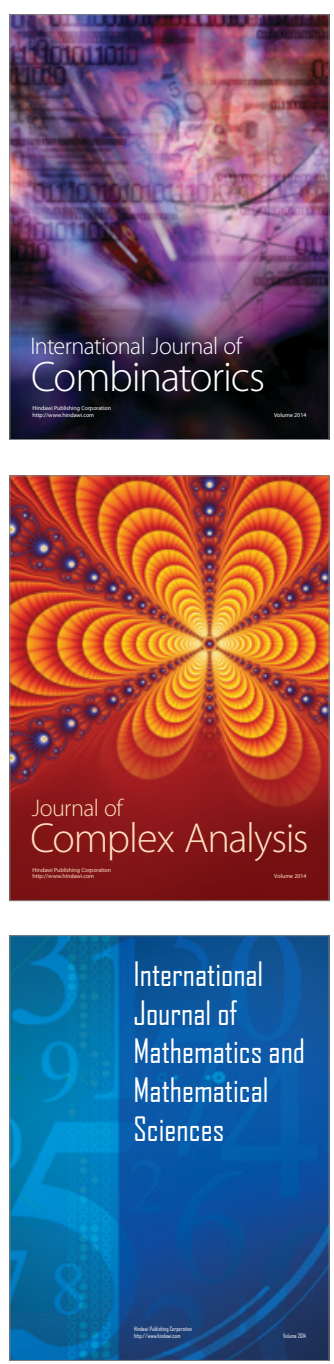
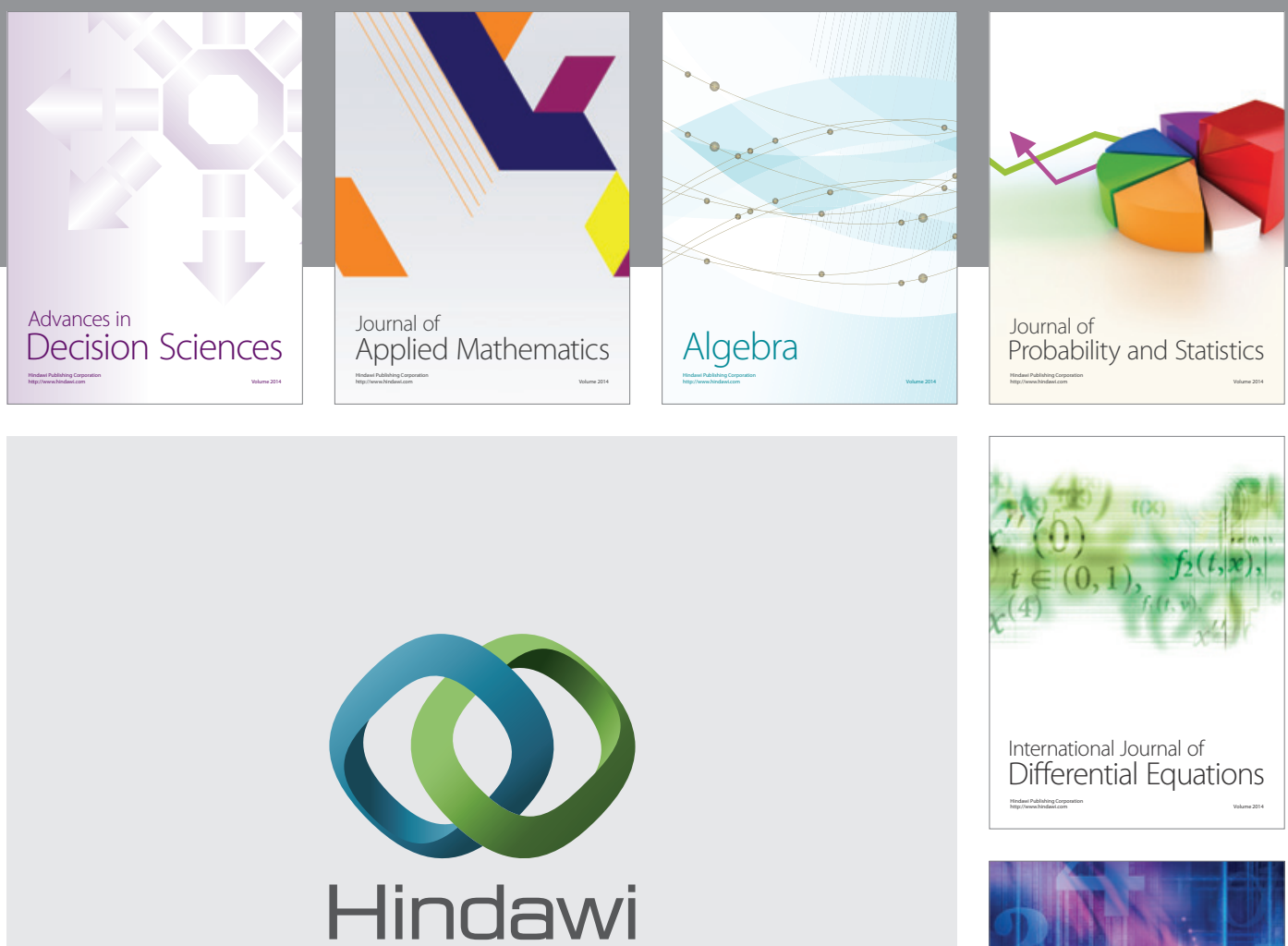

Submit your manuscripts at http://www.hindawi.com
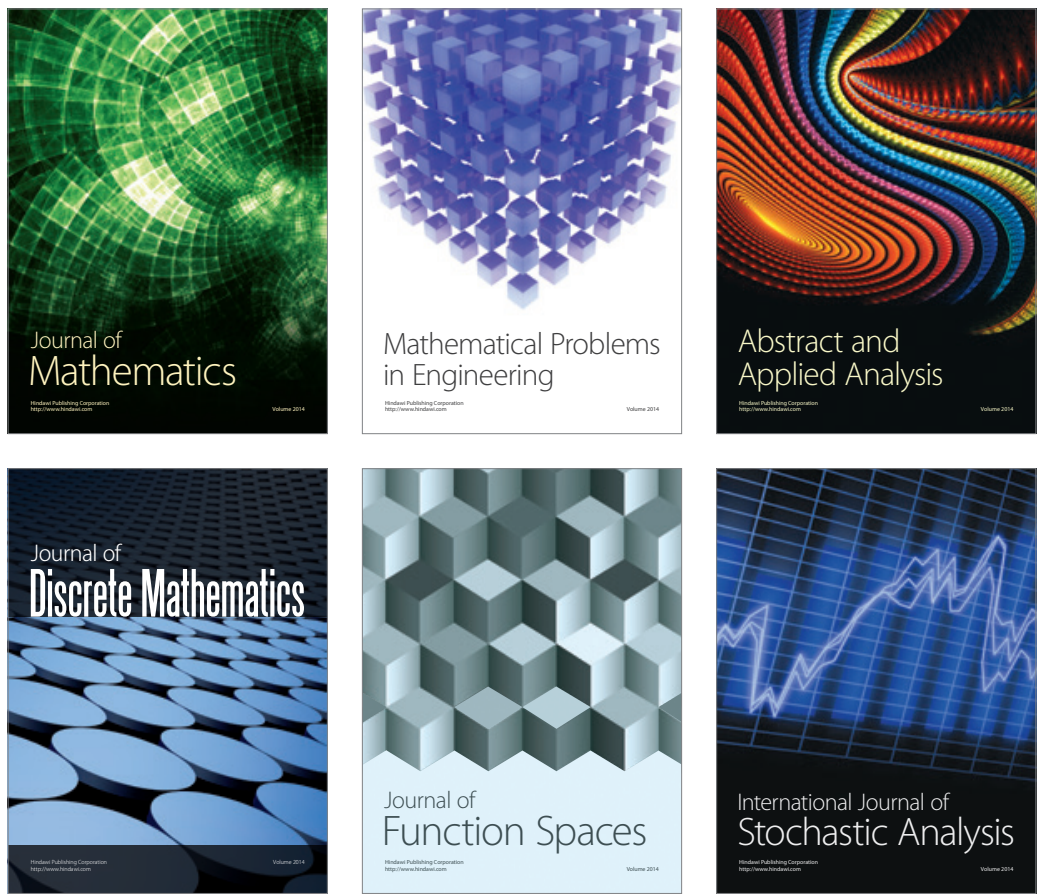

Journal of

Function Spaces

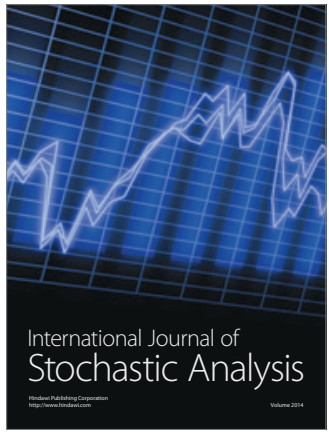

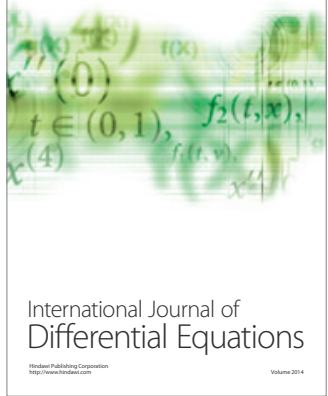
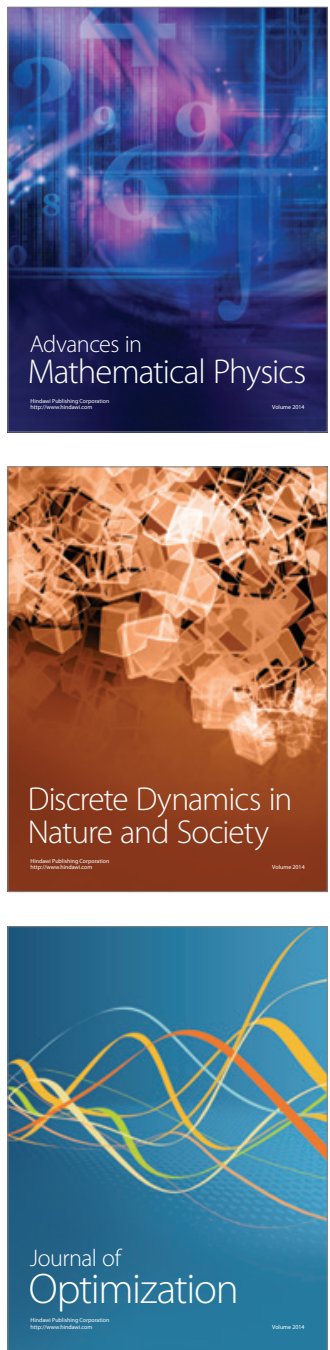